The Canadian Mineralogist

Vol. 39, pp. 331-339 (2001)

\title{
THE VALENCE AND SPECIATION OF SULFUR IN GLASSES BY X-RAY ABSORPTION SPECTROSCOPY
}

\author{
ELEONORA PARIS ${ }^{\S}$, GABRIELE GIULI AND MICHAEL R. CARROLL \\ Dipartimento di Scienze della Terra, Università di Camerino and INFM \\ (Istituto Nazionale Fisica della Materia) - Unità di Camerino, I-62032 Camerino, Italy \\ IVAN DAVOLI \\ Dipartimento di Fisica , Università di Roma "Tor Vergata", and INFM \\ (Istituto Nazionale Fisica della Materia) - Unità di Roma 2, I-00133 Roma, Italy
}

\begin{abstract}
The geochemical behavior of sulfur in magmas depends strongly on the oxidation state of sulfur, but this is not easily determined by standard analytical methods. We have measured XANES absorption spectra at the sulfur $K$-edge and have found that such measurements are useful to characterize the oxidation state and speciation of sulfur in silicate glasses of geological relevance. Measured spectra of a set of reference minerals show the effects of different oxidation states and coordination numbers of sulfur; there is a large shift in energy $(\sim 10-12 \mathrm{eV})$ of the sulfur $K$-edge between $\mathrm{S}^{2-}$ and $\mathrm{S}^{6+}$. This large and easily detectable difference makes possible the measurement of the valence of sulfur in unknown samples by measuring the shift in energy of the absorption edge. This approach is applicable to both crystalline and glassy materials, and useful results have been obtained on samples with as little as $450 \mathrm{ppm} \mathrm{S.} \mathrm{We} \mathrm{have} \mathrm{used} \mathrm{XANES} \mathrm{measurements} \mathrm{to} \mathrm{characterize} \mathrm{oxidation} \mathrm{state} \mathrm{and} \mathrm{speciation} \mathrm{of} \mathrm{sulfur}$ in a set of natural and synthetic sulfur-bearing glasses. The samples cover a range of composition from basaltic to almost rhyolitic, and some were synthesized over a range of pressure, temperature and oxygen fugacity; glass S content varies between 450 and $3000 \mathrm{ppm}$. XANES analyses, carried out in fluorescence mode at LURE, allowed determination of the sulfur oxidation state in all of the samples and clearly show that some samples contain a mixture of $\mathrm{S}^{2-}$ and $\mathrm{S}^{6+}$; no other sulfur species were observed. Quantitative determination of the abundance of sulfide and sulfate shows good agreement with independent measurements based on electron-microprobe determination of the wavelength shift of sulfur $K \alpha \mathrm{X}$-rays.
\end{abstract}

Keywords: sulfur, silicate glasses, X-ray absorption spectroscopy, XANES.

SOMMAIRE

Le comportement géochimique du soufre dans les magmas dépend fortement du taux d'oxydation du soufre, mais cet aspect n'est pas facile à documenter par les méthodes analytiques habituelles. Nous avons mesuré les spectres d'absorption XANES du soufre, en particulier du seuil d'absorption $K$, et nous avons trouvé ces mesures utiles pour caractériser le taux d'oxydation et la spéciation du soufre dans les verres silicatés d'importance géologique. Des spectres de référence ont été mesurés sur certains minéraux choisis pour montrer les taux d'oxydation et les coordinences distincts du soufre; il y a un décalage important en énergie $(\sim 10-12 \mathrm{eV})$ du seuil d'absorption $K$ entre le $\mathrm{S}^{2-}$ et le $\mathrm{S}^{6+}$. Cette différence majeure et facilement décelable rend possible la mesure de la valence du soufre dans des échantillons méconnus en examinant le déplacement de l'énergie associée au seuil de l'absorption. Ces mesures s'appliquent également à des matériaux cristallins ou vitreux, et mènent à des résultats utiles même dans des cas où la teneur en soufre est très faible, par exemple $450 \mathrm{ppm}$. Nous avons utilisé des mesures XANES pour caractériser le taux d'oxydation et la spéciation du soufre dans des verres naturels et synthétiques. Les échantillons correspondent à un intervalle de composition entre basaltique et presque rhyolitique, et certains ont été synthétisés sur un intervalle de pression, de température et de fugacité d'oxygène; la teneur en $\mathrm{S}$ des verres varie entre 450 et 3000 ppm. Les analyses XANES, faites en mode fluorescence à l'emplacement LURE, nous ont permis de déterminer le taux d'oxydation de tous les échantillons, et montrent clairement que certains échantillons contiennent un mélange de $\mathrm{S}^{2-}$ et de $\mathrm{S}^{6+}$; aucune autre valence de soufre n'a été observée. Une détermination quantitative de l'abondance de sulfure et de sulfate montre une bonne concordance avec les mesures fondées sur le décalage en longueur d'onde des rayons X $K \alpha$ du soufre, faites indépendemment avec une microsonde électronique.

(Traduit par la Rédaction)

Mots-clés: soufre, verres silicatés, spectroscopie d'absorption X, XANES.

§ E-mail address: paris@ camars.unicam.it 


\section{INTRODUCTION}

An atomistic-scale understanding of the way sulfur dissolves in silicate melts can help us to better understand the geochemical behavior of sulfur in magmas. For example, information about the parameters that affect sulfur solubility in magmas is crucial in attempts to use measurements of volcanic gas emissions to make inferences about subsurface movements of magma and probabilities of eruption. Sulfur is unusual among the common magmatic volatiles because over the range of typical magmatic oxidation states, the predominant form of sulfur changes from $\mathrm{S}^{2-}$ under reducing conditions to $\mathrm{SO}_{4}{ }^{2-}$ under oxidizing conditions (e.g., Nagashima \& Katsura 1973, Katsura \& Nagashima 1974, Carroll \& Rutherford 1988). The pattern of solubility of these two sulfur species differs considerably (e.g., see review in Carroll \& Webster 1994). Thus an understanding of variations in sulfur solubility and of volcanic degassing of sulfur requires information concerning sulfur oxidation state in magmas. In this paper, we show how X-ray absorption spectroscopy (XAS) of S-bearing glasses can provide information on the oxidation state of dissolved sulfur. The samples studied had been previously used to evaluate the oxidation state of sulfur by measuring the wavelength shift of sulfur $K \alpha \mathrm{X}$-rays with the electron microprobe (Carroll \& Rutherford 1988). More importantly, we show that the XAS results are consistent with the hypothesis that the $\mathrm{S}$ dissolved in silicate melts (glasses) of geological interest occurs predominantly as $\mathrm{SO}_{4}{ }^{2-}$ and $\mathrm{S}^{2-}$ (Carroll \& Rutherford 1988), with no evidence for significant quantities $(<\sim 5 \%)$ of sulfur with an intermediate oxidation state.

\section{BACKGROUND INFORMATION}

In silicate melts, sulfur dissolves mainly as sulfide under reducing condition and as sulfate under oxidizing conditions. The relative abundance of these two species in a melt is controlled by the equilibrium

$$
\mathrm{S}^{2-}{ }_{\text {melt }}+2 \mathrm{O}_{2 \text { gas }}=\left(\mathrm{SO}_{4}\right)^{2-}{ }_{\text {melt }}
$$

with an equilibrium constant

$$
\mathrm{K}_{1}=\left[\mathrm{SO}_{4}{ }^{2-}\right] /\left[\mathrm{S}^{2-}\right]\left\{f\left(\mathrm{O}_{2}\right)\right\}^{2}
$$

where $f$ denotes fugacity and square brackets denote activities. This expression indicates that a major factor controlling sulfur speciation is oxygen fugacity, $f\left(\mathrm{O}_{2}\right)$, as long as the activity coefficients of $\left(\mathrm{SO}_{4}\right)^{2-}$ melt and $\mathrm{S}^{2-}{ }_{\text {melt }}$, or their ratio, remain approximately constant.

Previous studies of the systematics of sulfur solubility provide information concerning the solution mechanisms of sulfur in melts. For anhydrous systems, many studies of melt compositions involved in commercial processes such as steel production (e.g., Fincham \& Richardson 1954, Abraham et al. 1960a, b) show that under reducing conditions, $\mathrm{S}$ dissolves as $\mathrm{S}^{2-}$, in a reaction that can be considered as an exchange for $\mathrm{O}^{2-}$ in the melt

$$
1 / 2 \mathrm{~S}_{2}+\mathrm{O}^{2-}=1 / 2 \mathrm{O}_{2}+\mathrm{S}^{2-}
$$

Since $\mathrm{S}^{2-}$ is much larger than $\mathrm{O}^{2-}$, the oxygen atoms available for exchange are likely those bound to network-modifying cations, instead of those associated with tetrahedrally coordinated $\mathrm{Al}^{3+}$ or $\mathrm{Si}^{4+}$. This inference is supported by the observation that solubility of sulfur is higher in more silica-poor melts, all other factors being equal (Fincham \& Richardson 1954, Abraham et al. 1960a, b). The positive correlation between sulfide solubility and $\mathrm{FeO}$ contents of the melt suggests a strong affinity of $\mathrm{S}^{2-}$ species with networkmodifying $\mathrm{Fe}^{2+}$ cations (Haughton et al. 1974, Mathez 1976, Carroll \& Rutherford 1985, Wallace \& Carmichael 1992).

Under oxidizing conditions, such as those used in commercial glass-making and in some subduction-related magmas (e.g., Pinatubo, El Chichón), sulfur dissolves mainly as sulfate, as indicated by the reaction

$$
1 / 2 \mathrm{~S}_{2}+3 / 2 \mathrm{O}_{2}+\mathrm{O}^{2-}=\left(\mathrm{SO}_{4}\right)^{2-}
$$

Sulfur solubility depends therefore on the fugacity of oxygen $f\left(\mathrm{O}_{2}\right)$, the fugacity of sulfur $f\left(\mathrm{~S}_{2}\right)$, and on the activity of $\mathrm{O}^{2-}$ anions in the melt. At intermediate oxidation states, $\mathrm{S}$ can occur as sulfide and sulfate species, with the relative proportions depending on oxidation state (Carroll \& Rutherford 1988, Wallace \& Carmichael 1994, Nilsson \& Peach 1993). Therefore, to understand the behavior of sulfur in melts, we need information on $\mathrm{S}$ speciation.

Sulfur speciation can be measured by wet-chemical analysis, but the methods are not simple; a significant mass of sample is required, and glass must be carefully separated from crystals in order to get reliable information on content and speciation of sulfur in the melt. The electron microprobe can also be used to determine $S$ speciation by measuring the wavelength of the $\mathrm{S} K \alpha \mathrm{X}$ rays. This is done by scanning the crystal spectrometer of the probe over the region of the $\mathrm{S} K \alpha$ peak, which shifts in wavelength by about $1.4 \mathrm{eV}$ between $\mathrm{S}^{2-}$ and $\mathrm{S}^{6+}$; the peak shifts can typically be measured to a precision of $\pm 10-15 \%$ (Carroll \& Rutherford 1988, Wallace \& Carmichael 1992, 1994). It is possible to use the measured shifts in wavelength to estimate the proportions of reduced and oxidized sulfur species in natural glasses if we assume that the $\mathrm{S} K \alpha$ peak shifts linearly with S oxidation state (Carroll \& Rutherford 1985, Wallace \& Carmichael 1994, Nilsson \& Peach 1993, Matthews et al. 1999). This assumption is the key to using measurements of wavelength shift to determine sulfur speciation (or oxidation state of the magma), and our new XANES measurements support the validity of this assumption. 


\section{XAS ANALYSIS FOR SUlfur}

In this paper, we address the topic of determination of oxidation state and speciation of sulfur in silicate glasses by XANES (X-ray absorption near-edge structure) spectroscopy. X-ray absorption spectroscopy (XAS) is a non-destructive, element-specific technique that is sensitive to the electronic structure, oxidation state, coordination number and local bonding geometry of a selected element, independent of the crystallinity of the material under investigation, and down to low concentrations of the absorber (Bianconi 1988). Although this is the first application of XANES to the study of sulfur in silicate glasses, X-ray absorption spectroscopy has been used previously to study $\mathrm{S}$ in a variety of natural materials, including minerals, coal, petroleum and related hydrocarbons, following many studies concerning the investigation of sulfur $K$-edge in organic and inorganic materials (e.g., Spiro et al. 1984, Huffman et al. 1995, Waldo et al. 1991). Li et al. (1995) have recently reported results of a comprehensive study of sulfur-bearing minerals with varying oxidation states of sulfur. They showed that a significant energy-shift occurs at the sulfur absorption $K$ and $L$ edges as a function of $\mathrm{S}$ oxidation state [as observed by Frank $e$ al. (1987) and George \& Gorbaty (1989) in studies of organic materials]. This shift can be used to evaluate the valence of unknown sulfur compounds, as the shift in energy of the absorption edge can be related to the difference in electron density between different oxidation states. The removal of a valence electron produces a decrease of the screening of core electrons, which in turn strengthens the core energy-levels. Therefore, an increase of oxidation states produces an increase of the binding energy of inner-shell $1 s$ and $2 p$ electrons and a shift of the sulfur $K$-edge toward higher energy.

Studies of sulfide minerals by X-ray absorption spectroscopy (e.g., Li et al. 1994a, b, c, Charnock et al. 1990, Sugiura 1981, Sugiura \& Muramatsu 1985) show that the edge shift depends not only on the binding energy of the inner shells, but also on the final states (i.e., the first unoccupied states). The electronic structure of $3 d$ element sulfides affects the edge chemical shift, with lower values for the compounds characterized by elements with partially occupied $3 d$ orbitals (metal $3 d-\mathrm{S}$ $3 s$ - and $3 p$-like states in the band gap) compared with those with fully occupied $3 d$ orbitals (metal $3 d-\mathrm{S} 3 s-$ and $3 p$-like states at the conduction-band minimum) (Li et al. 1995). Values of the energy-band gap are also positively correlated with the edge position.

XANES analysis has been applied successfully to the determination of the forms of sulfur in coal, where sulfur is a critical element controlling industrial use, and sulfur-removal techniques comprise a major research topic (Spiro et al. 1984, Huffman et al. 1991). These studies have shown that the oxidation state of sulfur in coal ranges from sulfide to sulfate, and XAS has been used to quantify the abundances of organic and inorganic forms of sulfur (Huffman et al. 1991, 1995, Premuzic et al. 1994).

XANES studies of sulfur in bitumens and asphaltenes (Kasray et al., 1994) and petroleums or petroleum source-rocks have been used to identify and quantify various compounds of sulfur (Waldo et al. 1991) and to document the correlation between sulfur speciation and depositional environment, thermal maturity and aromaticity. The same technique has been used successfully to investigate sulfur in biogenic and diagenetic carbonates; such studies show that $\mathrm{S}$ in the sulfate form substitutes for carbonate (Pingitore et al. 1995). Also, sulfonates have been detected in some organic-matter-rich marine sediments and found to be a novel and major component of organic sulfur in sedimentary rocks (Vairavamurthy et al. 1994).

\section{Methods ANd Materials}

The S $K$-edge spectra have been collected at LURE, Orsay (France) on the SA32 beam line of the SuperACO storage ring. This ring operates at $800 \mathrm{MeV}$ with an average stored current of $200 \mathrm{~mA}$, the actual value depending on the bunch mode ( 2 or 24). The SA32 beam line uses an upstream toroidal mirror and a two-crystal monochromator with an exit beam kept fixed by means of a cam. In the present experiment, we used two Ge (111) crystals, which allow a resolution of $0.9 \mathrm{eV}$ at $3000 \mathrm{eV}$. The incoming flux of photons has been monitored by the drain current from a $0.8 \mu \mathrm{m}$ aluminum foil, and the absorption spectra, by the fluorescence yield (FY) using a one-element germanium detector mounted in the horizontal plane oriented at $90^{\circ}$ to the incident Xray beam. The FY spectra have been obtained by monitoring the number of counts within the energy window of the detector output centered on the $\mathrm{S} K$ emission line. In the present work, no correction for self-absorption was necessary because the dilute nature of the glass samples produces a FY signal directly proportional to the absorption coefficient.

The samples $(\sim 50 \mathrm{mg}$ total) were prepared by finely grinding glasses and crystal chips to powder and mounting them on an Al plate (over an area of several $\mathrm{mm}^{2}$ ). All of the ground glass samples were treated multiple times in an ultrasonic bath filled with warm distilled water to remove any possible trace of crystalline sulfate [anhydrite, present as phenocrysts $(<2 \mathrm{vol} . \%)$ in some of the experimental samples], and washed with warm distilled water prior to drying for analysis. The high solubility of anhydrite in water makes this an effective procedure for removing crystalline sulfate; optical examination of the resulting powders verified the efficiency of this treatment. The sample of back-arc basalt glass (BAB) was not sulfide-saturated, so no treatment of the glass was necessary. Experimental glasses produced at more reducing conditions could not be ana- 
lyzed because all had dispersed grains of $\mathrm{FeS}$, and we could not find an effective way to separate sulfide-free glass from this material.

Energy calibration was carried out using crystalline sulfur, routinely measured during collection of the spectra. Standard data-reduction procedures were used to extract the XANES signals: the background has been subtracted from the spectra using a Victoreen function, and the spectra have been normalized to the high-energy part of the spectrum. The energy position of the edge has been determined from the first maximum of the spectrum derivative. Fitting of the XANES spectra was carried out using an arctangent baseline and mixed lorentzian-gaussian peak functions, and the areas of the peaks were used to quantify the proportions of sulfide and sulfate.

Minerals containing sulfur in different oxidation states have been used as reference compounds: they include native sulfur, gypsum, apatite, galena, pyrrhotite, sphalerite. All the reference materials have been previously characterized by powder X-ray diffraction. Details of the synthesis procedures of the experimental glasses studied here are reported in Carroll \& Rutherford (1985), and essential data on composition, sulfur content, and conditions of synthesis of the samples are summarized in Table 1 . The glass samples analyzed in this work have a limited range of bulk compositions (Table 1), and their total sulfur contents range between

TAELE I EXPERTMERTAL AND COMPOSITIONAL DATA FOR GLASSES LSED MK TEIS STLDY*

\begin{tabular}{|c|c|c|c|c|c|c|c|}
\hline sample & Composition & $\begin{array}{c}\text { wotal S } \\
\text { ppttu }\end{array}$ & $\begin{array}{l}3^{\bar{x}} \\
\%\end{array}$ & $\begin{array}{l}g, \\
\%\end{array}$ & $\underset{\mathbf{M F}^{\prime}}{\mathbf{F}}$ & $\underset{n}{T} \mathrm{C}$ & $M\left(O_{2}\right)$ \\
\hline BAE- -23 & Backnare basta $\dagger$ & $\begin{array}{l}500 \\
(70)\end{array}$ & 83 & 17 & NA & $\mathrm{NA}$ & \\
\hline $59 \mathrm{a}$ & $\begin{array}{l}\text { Dacite } \\
\text { Wt. St. Helens } \\
\text { FeO(tot) } 5.7 \text { wt. } \%\end{array}$ & $\begin{array}{l}2300 \\
(180)\end{array}$ & 12 & 88 & 210 & 1025 & \\
\hline $75 \mathrm{~b}$ & $\begin{array}{l}\text { Lacite } \\
\text { M1. 8L. Helens } \\
\text { FeO(tol) } 4.7 \text { wt.\% }\end{array}$ & $\begin{array}{l}3090 \\
(250)\end{array}$ & $\leq 5$ & $>95$ & 290 & 1025 & $3 \pi$ \\
\hline TJG & $\begin{array}{l}\text { Dacite } \\
\text { Mtt St. Helens } \\
\text { FeO(tot) } 3.9 \text { wt. } \%\end{array}$ & $\begin{array}{l}2950 \\
(250)\end{array}$ & $\leq 5$ & 255 & $20 n$ & 1425 & \\
\hline RES-610 & $\begin{array}{l}\text { Na-Ca silicale } \\
\text { Se below }\end{array}$ & 450 & $\therefore 5$ & 205 & 0.1 & & in \\
\hline
\end{tabular}

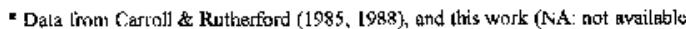

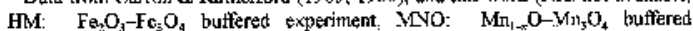
expertinent). The proportion of $\mathrm{S}^{2}$ and $\mathrm{S}^{\delta}$ was established by the $\mathrm{S} K$ a peak-shit method. Estimated errors of electron-microprube mensulements, based an their

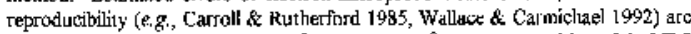
$-10 \%$ absolute Fror example, $20 \% \mathrm{~S}^{2}$ is $26 \pm 10 \% \mathrm{~S}^{2}$. The composition of the NBS

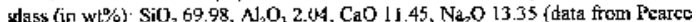

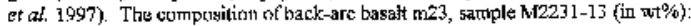
$\mathrm{SiO}_{2} 51.22, \mathrm{THO}, 1.52, \mathrm{Al}, \mathrm{O}_{1} 14.17, \mathrm{~F}=\mathrm{O} 11.66, \mathrm{M} 5 \mathrm{O} 6.85, \mathrm{CaO} 11.54, \mathrm{~N}_{2} \mathrm{O} 2.71$,

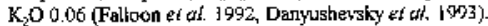

450 and $3000 \mathrm{ppm}$, as determined by electron-microprobe analysis.

\section{Results AND Discussion}

\section{Spectra of reference compounds}

Measured XANES spectra showing the $K$-edge absorption of sulfur in sulfur-bearing minerals used as reference materials are shown in Figure 1. They cover a range of oxidation states (from $\mathrm{S}^{2-}$ to $\mathrm{S}^{6+}$ ) and coordination geometries. The overall shape of the spectra and the energy position of $\mathrm{S} K$-edge show significant variability among different types of samples. The number, position and intensity of the spectral peaks depend mainly on the number and kind of first neighbors around the scattering element, but also on effects due to nextnearest-neighbor atoms and their back-scattering power. For example, in the spectra of galena $(\mathrm{PbS})$ and sphalerite $(\mathrm{ZnS})$ (Fig. 1), the shape of the spectra and also the energy position of the edge are affected by the different structure of these species, coordination numbers (sulfur is in 4-fold coordination in $\mathrm{ZnS}$ and in 6-fold coordina-

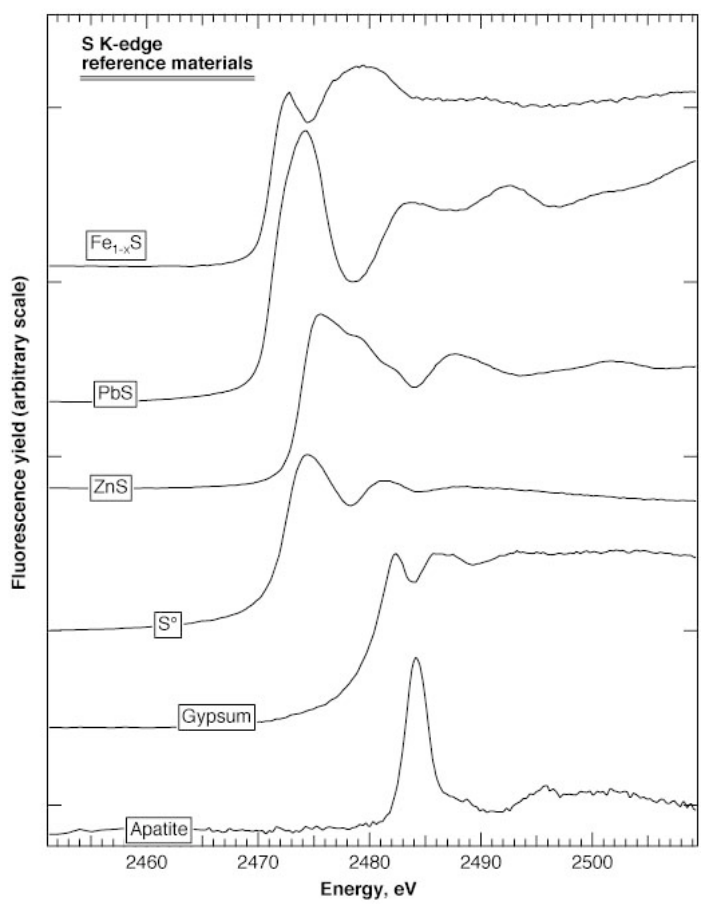

FIG. 1. Sulfur $K$-edge spectra of some S-bearing minerals used as reference in a range of oxidation state (from $\mathrm{S}^{2-}$ to $\mathrm{S}^{6+}$ ). Edge position and spectral features change dramatically with oxidation state, coordination number, local geometry around the absorber, and electronic structure. 
tion in $\mathrm{PbS}$ ), type of bond, and type of cation present. Similar observations can be made for sulfate minerals and to explain the differences observed between the apatite and gypsum spectra.

The edge shifts we observe depend strongly on the oxidation state and the electronic structure. For example,

TABLE 2 XAMES DATA FOR SI IT MR IN STMNDARDS

\begin{tabular}{|c|c|c|c|}
\hline sample & $\begin{array}{c}\text { iflcal } \\
\text { formula }\end{array}$ & $\begin{array}{c}\text { oxidation state } \\
\text { of sulfur }\end{array}$ & $\underset{\mathrm{eV}}{K \mathrm{~V}^{*}}$ \\
\hline Sulfut & $\$$ & 0 & 2472.6 \\
\hline Galenat & $P \nleftarrow S$ & -2 & 2471.2 \\
\hline Sphalerite & $\operatorname{ZnS}$ & 2 & 2474.0 \\
\hline Pymhetite & $\mathrm{Fe}_{\mathrm{y}-\mathbf{z}^{3}} \mathrm{~s}$ & -2 & 2471.1 \\
\hline Gypsum & $\mathrm{CeSO}_{4} \cdot 2 \mathrm{H}_{2} \mathrm{O}$ & -6 & 2481.1 \\
\hline Apatite & $\mathrm{Ca}_{3}\left(\mathrm{PO}_{4}\right)_{3}(\mathrm{OH}, \mathrm{F}, \mathrm{CI})$ & -6 & 2483.1 \\
\hline
\end{tabular}

Menergy position $(=0.2 \mathrm{gV})$. The aputite is gulfate-bearins, fom Durango, Mlexico

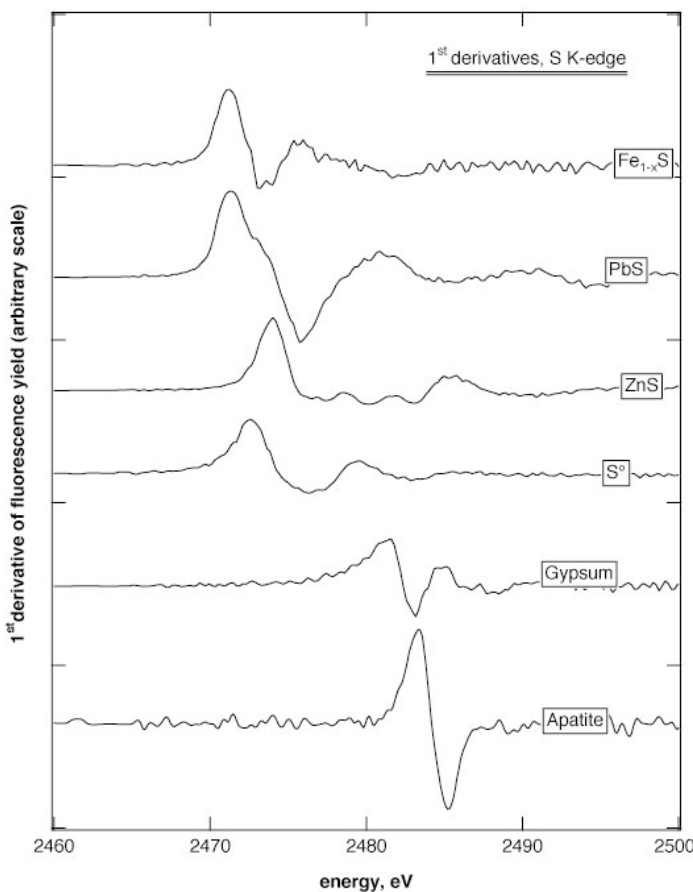

FIG. 2. First-derivative spectra, used to evaluate the energy position of the edge. Here, a comparison is shown between the various reference materials, illustrating the large difference in edge position and the similarities of spectra for samples with the same oxidation state of sulfur. among the spectra for the various minerals shown in Figure 1 , the $\mathrm{S} K$-edge of sulfide minerals $(\mathrm{PbS}, \mathrm{ZnS}$, $\mathrm{Fe}_{1-x} \mathrm{~S}$ ) lies at energy values near that for elemental $\mathrm{S}$, whereas the edge for gypsum and sulfate-bearing apatite occurs at a higher energy (Table 2). The difference in energy observed between the spectra of sulfide and sulfate minerals is $\sim 10-12 \mathrm{eV}$, and the position of the edge can be evaluated precisely from first derivatives of the fluorescence signal (Fig. 2). The data on the energy of the absorption edge for the standards versus $\mathrm{S}$ oxidation state are shown in Figure 3, which can be used to estimate the oxidation state of an unknown compound by looking at the energy shift of the edge.

\section{The spectra of silicate glasses}

Sulfur XANES spectra of natural and synthetic glasses with sulfur contents ranging from 450 to 3000 ppm (Table 1) are shown in Figure 4. Besides the XANES results, sulfur speciation in all of the samples (Table 1) has been estimated using the electron-microprobe-based peak-shift method described in Carroll \& Rutherford (1988). In spite of the low sulfur content of

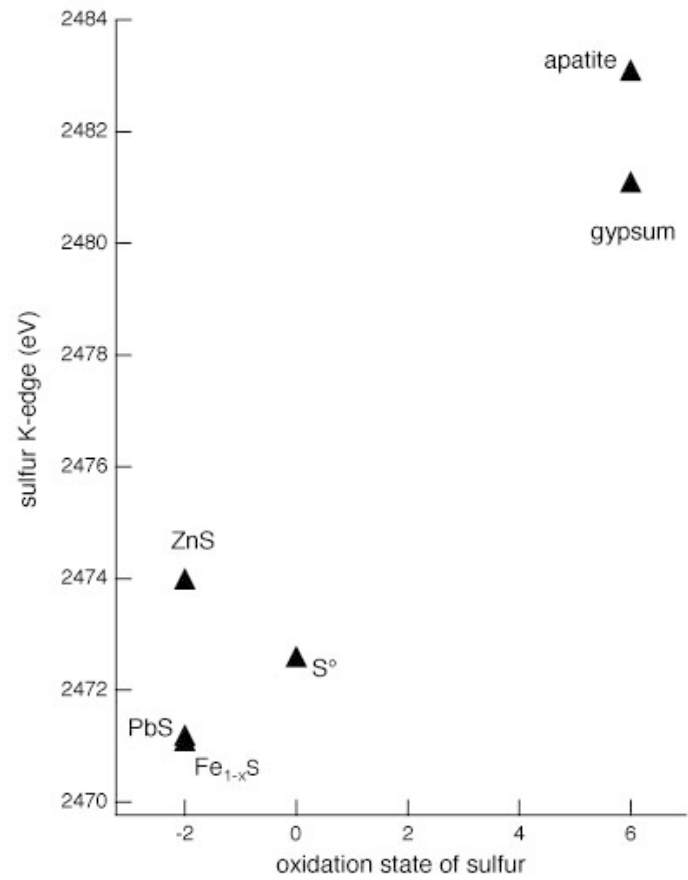

FIG. 3. The relation between energy of the sulfur $K$-edge and oxidation state of sulfur for a series of reference compounds. The large difference in energy between sulfide and sulfate $(\sim 12 \mathrm{eV})$ allows use of the energy of the absorption edge to estimate the oxidation state of sulfur. 


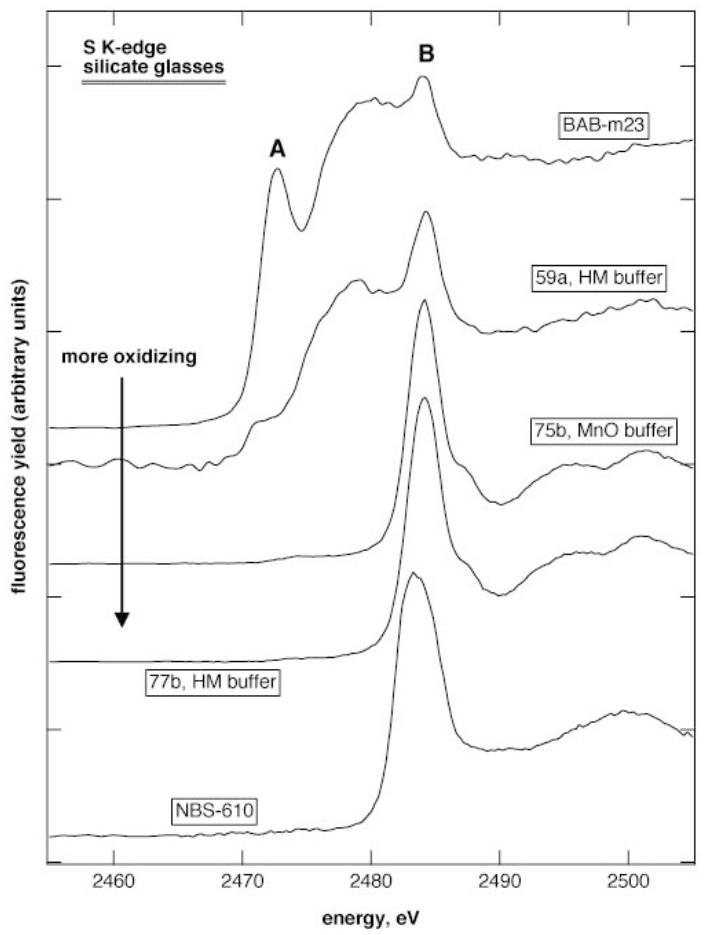

FIG. 4. Sulfur $K$-edge spectra of some S-bearing silicate glasses characterized by different bulk-composition, total sulfur content and oxygen fugacity. Edge position and shape of the spectra suggest the presence of $\mathrm{S}^{6+}$ mainly in the more oxidized samples (the first three from the bottom) and a coexistence of sulfide and sulfate species in the other two. Note that the spectra for BAB-m23 and 59a have been smoothed slightly using a second-order binomial smoothing algorithm (Marchand \& Marmet 1983). This does not affect the determination of the energy position of the edge, but it does help to better show the lower-intensity peaks.

some of the samples, it was possible to obtain XANES spectra with acceptable signal-to-noise ratio. The spectra are composed of one or more main peaks in the energy region around the edge, and they are labeled with letters. The glass spectra can be divided into two distinct groups, on the basis of both the shape of the XANES spectrum and the energy position of the edge, and they have been arranged in the figure according to their experimental or, in the case of the natural sample, inferred conditions of oxidation (Table 1 ). The $K$-edge for samples $59 \mathrm{a}$ and $\mathrm{BAB}-\mathrm{m} 23$ is located at distinctly lower energy compared with those of NBS-610, 75b, and $77 \mathrm{~b}$. The determination of the energy value of the edges by first derivatives gives a difference of $12 \mathrm{eV}$ between the two groups of spectra. On the basis of a comparison with reference materials and the energy of the absorption edges, samples NBS-610, 75b, and 77a have sulfate as the predominant form of $\mathrm{S}$, whereas the spectra for samples $\mathrm{BAB}-\mathrm{m} 23$ and 59 a show evidence of both sulfide and sulfate, on the basis of the presence of peaks at $\sim 2473$ and $\sim 2484 \mathrm{eV}$. The differences in intensity of these two peaks is related to the amounts of oxidized and reduced sulfur. It is important to note that there is no indication of the presence of other forms of sulfur with a valence intermediate between -2 and +6 . These observations demonstrate that even in the samples with diluted mixed-valence sulfur, the XANES measurements are extremely sensitive because the features characteristic of each type of sulfur species are easily recognizable owing to the large difference in energy of the absorption edges in sulfide and sulfate. This contrasts with electron-microprobe-based measurements of $\mathrm{S}$ speciation, where the total shift of only $\sim 1.4 \mathrm{eV}$ between sulfide and sulfate results in uncertainties in the proportions of sulfur species of at least $10 \%$ absolute (or even larger with sulfur-poor samples).

\section{Quantitative determination of sulfur species}

A quantitative evaluation of the relative amount of the two different sulfur species in the glasses analyzed by XAS can be extracted by modeling the spectra as being composite, with contributions from different species. In the case of a glass sample containing only one sulfur species, all the sulfur content can be associated straighforwardly to the $\mathrm{S}$ species determined by XANES. For example, in sample NBS-610, all the sulfur is present as sulfate $\left(\mathrm{S}^{6+}\right.$, i.e., $\left.\mathrm{SO}_{4}{ }^{2-}\right)$, and there is no evidence for the presence of any reduced sulfur $(<1-2 \%)$.

In the samples BAB-m23 and 59a, where both oxidized $\left(\mathrm{SO}_{4}{ }^{2-}\right)$ and reduced $\left(\mathrm{S}^{2-}\right)$ sulfur species have been detected, determination of the proportions of the two species requires the determination of the area of the peaks related to $\mathrm{S}^{2-}$ and $\mathrm{SO}_{4}{ }^{2-}$ (respectively, $\mathrm{A}$ and $\mathrm{B}$ in Fig. 4) by fitting the experimental spectra with appropriate parameters and by establishing a relationship between the XANES peaks and the different species of sulfur. The determination of the intensity of XANES spectral features can be carried out by fitting the experimental curves with an arctangent function, representing the edge step, with lorentzian-gaussian functions reproducing the peaks of the XANES region, in particular those related to $\mathrm{S}^{2-}$ and $\mathrm{SO}_{4}{ }^{2-}$. To quantify the relationship between the area of the curves and the amount of sulfur of different types, various procedures have been adopted by authors dealing with a variety of compounds. For sulfur in coal, Gorbaty et al. (1991) made approximate quantification of $\mathrm{S}$ by systematic analysis of the third derivative of the spectra, whereas Huffman et al. (1991, 1995) used a method based on least-squares analysis of XANES spectra, in which the peak areas were converted to sulfur concentrations using calibration constants derived from mixtures of standard compounds. Other authors proposed methods based on weighed addition of XANES spectra (Spiro et al. 1984) 
and constructed spectra of unknown samples by digitally combining the spectra of model compounds (Brown et al. 1992, Kasrai et al. 1994).

As our glasses have also been analyzed using the wavelength shift of the S $K \alpha \mathrm{X}$-rays obtained independently by electron microprobe (Carroll \& Rutherford 1988), we made a direct comparison between the microprobe-based data on speciation and those obtained from the fit of XANES peaks by using lorentziangaussian peaks and arctangent backgrounds on spectra normalized to the same maximum value (i.e., assuming simple linear proportionality between peak area and amount of absorber atom). The results (Table 3) indicate, for sample $59 \mathrm{a}$, a $\mathrm{S}^{6+}$ content of $81 \%$ of the total sulfur (compared with $89 \pm 15 \%$ as determined by electron microprobe; Table 1), whereas for the sample $\mathrm{BAB}-\mathrm{m} 23$, we found a $\mathrm{S}^{6+}$ content of $24 \%$ (microprobe data: $17 \pm 10 \% \mathrm{~S}^{6+}$ ). It is not clear why sample 59 a has considerably more sulfide than the other HM-buffered (HM: hematite-magnetite) experimental glass (sample $77 \mathrm{~b}$ : $<5 \%$ sulfide based on electron microprobe peakshift measurements), but both the XANES and microprobe-based wavelength-shift measurements on this sample indicate that $10-20 \%$ of the sulfur is sulfide; it is possible that although the buffer still contained some hematite, the sample was somewhat more reduced, since the kinetics of buffer oxidation-reduction may be slower that equilibration of hydrogen fugacities between internal and buffer capsules (e.g., hematite present in the buffer assemblage might be effectively removed from the system if it is surrounded by an overgrowth of magnetite, and this might not be seen in examining a grain mount of the buffer assemblage). Within the estimated error limits of $10-15 \%$, the XANES and microprobebased wavelength shifts give results that are indistinguishable.

The XANES measurements thus appear to be very sensitive, even where the concentrations of the two species of sulfur and total sulfur are low. In fact, the spec-

TABLE 3. XANES DATA FOR SULFUR R GLABSES

\begin{tabular}{|c|c|c|c|c|c|c|c|c|}
\hline \multirow{2}{*}{$\begin{array}{l}\text { samples } \\
59 \text { a }\end{array}$} & \multicolumn{2}{|c|}{$K$-edge } & \multicolumn{2}{|c|}{$\begin{array}{c}\text { peak A } \\
\text { position intensity }\end{array}$} & \multicolumn{2}{|c|}{$\begin{array}{c}\text { peak B } \\
\text { position inrensity }\end{array}$} & \multirow{2}{*}{$\begin{array}{l}g^{2-} \\
7 / 4 \\
- \\
19\end{array}$} & \multirow{2}{*}{$\begin{array}{l}S^{6} \\
\% \\
8]\end{array}$} \\
\hline & $247 \perp 4$ & 2483.4 & $2472, \mathrm{D}$ & 020 & 2484.2 & 0.87 & & \\
\hline$B A B-m 23$ & 2470.3 & 2483.3 & 2472.7 & 0.80 & 24840 & 0.26 & 76 & 24 \\
\hline XES-610 & 2487,2 & - & - & - & 2483.6 & - & 0 & 100 \\
\hline $75 b$ & 2452.8 & - & - & - & 24822 & - & $\ll 5$ & $>95$ \\
\hline $7 \mathrm{~Tb}$ & 24829 & - & - & - & 24842 & - & $<5$ & $>55$ \\
\hline
\end{tabular}

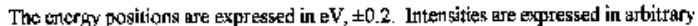
units. Ihey wery uhtained congideriag the area of fitted ptaks ahowe the aretangent baseline. tra in Figure 4 show that whereas sample NBS-610 (synthesized in air at $1 \mathrm{~atm}$ ) is all sulfate, the samples $75 \mathrm{~b}$ and $77 \mathrm{~b}$, although very similar to NBS-610, have a small quantity of $\mathrm{S}^{2-}$, as testified by the presence of the small but detectable peak at about $2474 \mathrm{eV}$ (i.e., the background is not perfectly flat before the edge like it is for NBS-610. These observations are in agreement with the slightly more reduced nature of these glasses (HM buffer) and with the inferences from the electronmicroprobe data indicating $\sim 95 \% \mathrm{SO}_{4}{ }^{2-}$ (Table 1 ).

\section{Structural information}

From an analysis of the experimental spectra and a comparison with the reference materials, it is possible to obtain information on the structural and chemical environment around the sulfur atoms. In this study, we do not report EXAFS spectra, since the sulfur is too dilute to give spectra with signal-to-noise suitable for refinement of the EXAFS data. Therefore, we are unable to determine $\mathrm{S}$ bond distances in the polyhedra. However, the XANES spectra also can give structural information, especially by using suitable reference materials and theoretical calculations (e.g., Brown et al. 1995).

As shown in Figure 4, the spectra of the glasses 59a and $\mathrm{BAB}-\mathrm{m} 23$ are very similar in shape, although the intensities of peak $\mathrm{A}$ and $\mathrm{B}$ vary as a function of the predominance of the proportions of $\mathrm{S}^{2-}$ or $\mathrm{SO}_{4}{ }^{2-}$ in the glass. This feature tells us that the local geometry and chemistry around each type of sulfur atom in these glasses is the same, i.e., $\mathrm{S}^{2-}$ (or $\mathrm{S}^{6+}$ ) is surrounded by the same type of first neighbors in both glasses. Also, by looking at the spectra of the reference materials reported in this paper (and others reported in the literature), we observe that the shape of the spectra (especially BAB-m23, the most strongly reduced glass) approximates very well the spectrum of pyrrhotite (Fig. 1) and differs greatly from the spectra of pyrite $\left(\mathrm{Fe}_{2} \mathrm{~S}: \mathrm{Li}\right.$ et al. 1995) and other sulfides (PbS, ZnS; Fig. 1). This finding suggests that in these glasses, $\mathrm{S}^{2-}$ atoms are surrounded by iron atoms in a six-fold coordination, with a geometry resembling that of pyrrhotite $\left(\mathrm{FeS}_{1-x}\right)$, where sulfur lies at the center of a trigonal prism of iron atoms.

Considering the spectra characterized by abundant oxidized sulfur, we observe that the two oxidized dacitic glasses (samples 75b, 77b) have virtually identical spectra. These differ considerably from the spectrum of the synthetic NBS-610 glass. These samples all are dominated by oxidized sulfur, but there are marked differences in both the width of the main peak (B) and in the features at energies higher than that of the main peak $(>2485 \mathrm{eV})$. The larger width of peak B suggests that there is more than one type of neighboring atom associated with the $\mathrm{SO}_{4}{ }^{2-}$ groups present in the NBS-610 glass, which is rich in both sodium $\left(13.35 \mathrm{wt} \% \mathrm{Na}_{2} \mathrm{O}\right)$ and calcium $(11.45 \mathrm{wt} \% \mathrm{CaO})$. 


\section{Conclusions}

In this study, we have shown for the first time how the analysis of X-ray absorption spectra of sulfur can give information on the oxidation state and local bonding environment of sulfur in glasses of geological interest. The new results indicate that sulfide $\left(\mathrm{S}^{2-}\right)$ and sulfate $\left(\mathrm{S}^{6+}\right)$ are the predominant forms of sulfur in glasses formed over a broad range of oxidation states (above nickel - nickel oxide); no evidence has been found to support the occurrence of $\mathrm{S}$ with intermediate states of oxidation. The large observed shift in absorption-edge energy for sulfide and sulfate $(\sim 12 \mathrm{eV})$ means that absorption peaks for these forms are clearly distinguishable and allow reliable identification of the oxidation state of the sulfur species. We have also shown that it is possible to quantitatively evaluate the proportion of each sulfur species in the glasses by peak-fitting procedures and that the results are in good agreement with electron-microprobe-based peak-shift data.

\section{ACKNOWLEDGEMENTS}

We thank G. Rossman for kindly providing some of the minerals used as standards, and the LURE staff, in particular M. Pompa, for technical help during collection of the spectra. The manuscript benefitted from helpful reviews by B. Scailet and N. Metrich and detailed editorial comments from R.F. Martin. This work was supported by grants from CNR, MURST and Università di Camerino (Cofinanziamento99) to EP and from the European Union Environment Program to MRC. We are pleased to contribute this work to a special issue of The Canadian Mineralogist dedicated to Peter L. Roeder, a true pioneer in studies of the geochemistry of sulfur in magmas.

\section{REFERENCES}

AbraHAM, K.P., Davies, M.W. \& Richardson, F.D. (1960a): Sulfide capacities of silicate melts. I. J. Iron Steel Inst. 196, 309-312.

$\&$ (1960b): Sulfide capacities of silicate melts. II. J. Iron Steel Inst. 196, 313-317.

BiAnCONI, A. (1988): XANES spectroscopy. In X-Ray Absorption. Principles, Applications Techniques of EXAFS, SEXAFS and XANES (D.C. Koningsberger \& R. Prins, eds.). John Wiley \& Sons, New York, N.Y. (573-662).

Brown, G.E., FARgES, F. \& CALAS, G. (1995): X-ray scattering and X-ray spectroscopy studies of silicate melts. In Structure, Dynamics and Properties of Silicate Melts (J.F. Stebbins, P.F. McMillan \& D.B. Dingwell, eds.). Rev. Mineral. 32, 317-410.

Brown, J.R., Kasrai, M., Bancroft, G.M., Tan, K.H. \& CHEN, J.M. (1992): Direct identification of organic sulfur species in Rasa coal from sulfur L-edge X-ray absorption near edge spectra. Fuel 71, 649-653.

Carroll, M.R. \& Rutherford, M.J. (1985): Sulfide and sulfate saturation in hydrous silicate melts. J. Geophys. Res. 90, C601-C612.

\& (1988): Sulfur speciation in hydrous experimental glasses of varying oxidation state: results from measured wavelength shifts of sulfur X-rays. Am. Mineral. 73, 845-849.

\& WeBSTER, J.D. (1994): Solubilities of sulfur, noble gases, nitrogen, chlorine, and fluorine in magmas. In Volatiles in Magmas (M.R. Carroll \& J. Holloway, eds.). Rev. Mineral. 30, 231-279.

Charnock, J., Garner, C.D., Pattrick, R.A.D. \& Vaughan, D.J. (1990): An EXAFS study of thiospinel minerals. Am. Mineral. 75, 247-255.

Danyushevsky, L.V., Falloon, T.J., Sobolev, A.V., Crawford, A.J., Carroll, M.R. \& Price, R.C. (1993): The $\mathrm{H}_{2} \mathrm{O}$ content of basalt glasses from southwest Pacific back-arc basins. Earth Planet. Sci. Lett. 117, 347-362.

Falloon, T.J., Malahoff, A., Zonenshain, L.P. \& Bogdanov, Y. (1992): Petrology and geochemistry of back-arc basin basalts from the Lau spreading ridges at $15^{\circ}$, $18^{\circ}$ and $19^{\circ}$ S. Mineral. Petrol. 47, 1-35.

Fincham, C.J.B. \& Richardson, F.D. (1954): The behavior of sulfur in silicate and aluminate melts. Proc. R. Soc. London 223A, 40-62.

Frank, P., Hedman, B., Carlson, R.M.K., Tyson, T.A., Roe, A.L. \& Hodgson, K.O. (1987): A large reservoir of sulfate and sulfonate residues within plasma cells from Ascidia ceratodes revealed by X-ray absorption near-edge structure spectroscopy. Biochem. 26, 4975-4976.

George, G.N. \& Gorbaty, M.L. (1989): Sulfur K-edge x-ray absorption spectroscopy of petroleum asphaltenes and model compounds. J. Am. Chem. Soc. 111, 3182-3186.

Gorbaty, M.L., George, G.N. \& Kelemen, S.R. (1991): Direct determination and quantification of sulfur forms in heavy petroleum and coal: sulfur K-edge X-ray absorption and X-ray photoelectron spectroscopic approaches. Am. Chem. Soc., Symp. Ser. 461, 127-136.

Haughton, D.R., Roeder, P.L. \& Skinner, B.J. (1974): Solubility of sulfur in mafic magmas. Econ. Geol. 69, 451-467.

Huffman, G.P., Mitra, S., Huggins, F.E., Shah, N., Vaidya, S. \& LU, F. (1991): Quantitative analysis of all major forms of sulfur in coal by X-ray absorption fine structure spectroscopy. Energy Fuels 5, 574-581.

, Shah, N., Huggins, F.E., Stock, LM, ChatterJee, K, Kilbane, J.J., Chou, M.I.M. \& Buchanan, D.H. (1995): Sulfur speciation of desulfurized coals by XANES spectroscopy. Fuel 74, 549-555. 
Kasrai, M., Bancroft, G.M., Brunner, R.W., Jonasson, R.G., Bown, J.R., Tan, K.H. \& Feng, Xinghong (1994): Sulfur speciation in bitumens and asphaltenes by X-ray absorption fine-structure spectroscopy. Geochim. Cosmochim. Acta 58, 2865-2872.

Katsura, T. \& NAgashima, S. (1974): Solubility of sulfur in some magmas at $1 \mathrm{~atm}$ pressure. Geochim. Cosmochim. Acta 38, 517-531.

Li, Dien, Bancroft, G.M., Kasrai, M., Fleet, M.E., Feng, XINGHONG \& TAN, K.H. (1995): S K- and L-edge X-ray absorption spectroscopy of metal sulfides and sulfates: applications in mineralogy and geochemistry. Can. Mineral. 33, 949-960.

\& YANG, B.X. (1994a): Sulfur K- and L-edge XANES and electronic structure of zinc, cadmium and mercury monosulfides: a comparative study. J. Phys. Chem. Solids 55, 535-543.

$\&$ TAN,

K. (1994b): Sulfur K- and L-edge XANES and electronic structure of some copper sulfide minerals. Phys. Chem. Minerals 21, 317-324.

YANG, B.X.,

Feng, Xinghong, Tan, K. \& Peng, Minsheng (1994c): Sulfur K- and L-edge X-ray absorption spectroscopy of sphalerite, chalcopyrite and stannite. Phys. Chem. Minerals 20, 489-499.

MARChAND, P. \& MARMET, L. (1983): Binomial smoothing filter: a way to avoid some pitfalls of least-squares polynomial smoothing. Rev. Sci. Instrum. 54, 1034-1041.

Mathez, E.A. (1976): Sulfur solubility and magmatic sulfides in submarine basalt glass. J. Geophys. Res. 81, 4269-4276.

Matthews, S.J., MoncriefF, D.H.S. \& CARroll, M.R. (1999): Empirical calibration of the sulphur valence oxygen barometer from natural and experimental glasses: method and applications. Mineral. Mag. 63, 421-431.

NAgashima, S. \& Katsura, T. (1973): The solubility of sulfur in $\mathrm{Na}_{2} \mathrm{O}-\mathrm{SiO}_{2}$ melts under various oxygen partial pressures. Bull. Chem. Soc. Japan 46, 3099-3103.

NiLsson, K. \& PeACH, C.L. (1993): Sulfur speciation, oxidation state and sulfur concentration in back-arc magmas. Geochim. Cosmochim. Acta 57, 3807-3813.
Pearce, N.J.G., Perkins, W.T., Westgate, J.A., Gorton, M.P., JaCKSON, S.E., NeAL, C.R. \& Chenery, S.P. (1997): A compilation of new and published major and trace element data for NIST SRM 610 and 612 glass reference materials. Geostandards Newsletter 21, 115-144.

Pingitore, N.E., Meitzner, G. \& Love, K.M. (1995): Identification of sulfate in natural carbonates by X-ray absorption spectroscopy. Geochim. Cosmochim. Acta 59, 2477-2483.

Premuzic, E.T., Lin, M.S. \& Maniwitz, B. (1994): The significance of chemical markers in the bioprocessing of fossil-fuels. Fuel Proc. Techn. 40, 227-239.

Spiro, C.L., Wong, J., Lytle, F.W., Greegor, R.B., Maylotte, D.H. \& LAMson, S.H. (1984): X-ray absorption spectroscopic investigation of sulfur sites in coal: organic sulfur identification. Science 226, 48-50.

SugIURA, C. (1981): Sulfur K X-ray absorption spectra of FeS, $\mathrm{FeS}_{2}$ and $\mathrm{Fe}_{2} \mathrm{~S}_{3}$. J. Chem. Phys. 74, 215-217.

\& Muramatsu, S. (1985): Sulfur K X-ray absorption-edge structures and electronic states of transition-metal sulfides MS and $\mathrm{MS}_{2}(\mathrm{M}=\mathrm{Fe}, \mathrm{Co}, \mathrm{Ni})$. Phys. Stat. Sol. B129, K157-K161.

Vairavamurthy, A., Zhou, Weiging, Eglinton, T. \& MANOwITZ, B. (1994): Sulfonates - a novel class of organic sulfur-compounds in marine sediments. Geochim. Cosmochim. Acta 58, 21, 4681-4687.

Waldo, G.S., Carlson, R.M.K., Moldowan, J.M., Peters, K.E. \& Penner-Hahn, J.E. (1991): Sulfur speciation in heavy petroleums: Information from X-ray absorption near-edge structure. Geochim. Cosmochim. Acta 55, 801814.

WAllace, P.J. \& CARMichael, I.S.E. (1992): Sulfur in basaltic magmas. Geochim. Cosmochim. Acta 56, 1863-1874.

$\&$ (1994): S speciation in submarine basaltic glasses as determined by measurements of $\mathrm{SK} \alpha \mathrm{X}$ ray wavelength shifts. Am. Mineral. 79,161-167.

Received August 19, 2000, revised manuscript accepted March 17, 2001. 